\title{
Sorbus commixta water extract induces apoptotic cell death via a ROS-dependent pathway
}

\author{
SEONG-CHEOL MOON ${ }^{1,2^{*}}$, HEE-JUNG CHOI ${ }^{1,2 *}$, TAE-WOOK CHUNG ${ }^{1,2}$, JUNG-HEE LEE $^{2}$, \\ SYNG-OOK LEE ${ }^{3}$, MYEONG HO JUNG ${ }^{1}$, BYUNG JOO KIM ${ }^{1}$, JUN-YONG CHOI ${ }^{1,4}$ and KI-TAE HA ${ }^{1,2,4}$ \\ ${ }^{1}$ Department of Korean Medical Science, School of Korean Medicine and ${ }^{2}$ Korean Medical Research Center for \\ Healthy Aging, Pusan National University, Yangsan, Gyeongnam 50612; ${ }^{3}$ Department of Food Science and Technology, \\ Keimyung University, Daegu 42601; ${ }^{4}$ Korean Medical Clinical Research Center, Pusan National \\ University Hospital, Yangsan, Gyeongnam 50612, Republic of Korea
}

Received January 12, 2017; Accepted April 6, 2017

DOI: $10.3892 / \mathrm{ol} .2018 .9217$

\begin{abstract}
The stembark of Sorbus commixta Hedl. has been used for treating asthma, bronchitis, gastritis and edema. However, the anticancer and proapoptotic effects of the water extract of the stembark of S. commixta (SCE) remain unknown. In the present study, it was shown that SCE inhibited the cell viability of the hepatocellular carcinoma cell lines Hep3B and HepG2, and of the colon carcinoma cell line HCT116. DNA content analysis indicated that SCE increased the sub-G1 population of HCT116 cells. In addition, degradation of nuclear DNA and levels of proapoptotic cascade components, including caspase-9, caspase-3 and poly ADP-ribose polymerase, were augmented by SCE treatment. Mitochondrial membrane potential and the ratio of B-cell lymphoma-2 (Bcl-2)/Bcl-2-associated X protein (Bax) were also reduced. Furthermore, SCE increased the expression of proapoptotic proteins, including p21, p27 and p53. Mouse double minute 2 homology, a negative regulator of p53, was cleaved by SCE treatment. Intracellular reactive oxygen species (ROS)
\end{abstract}

Correspondence to: Professor Ki-Tae Ha, Department of Korean Medical Science, School of Korean Medicine, Pusan National University, 49 Busandaehak-ro, Yangsan, Gyeongnam 50612, Republic of Korea

E-mail: hagis@pusan.ac.kr

*Contributed equally

Abbreviations: SCE, Sorbus commixta stembark water extract; ROS, reactive oxygen species; PARP, poly ADP-ribose polymerase; TMRM, tetramethylrhodamine methyl ester perchlorate; DMSO, dimethyl sulfoxide; FACS, fluorescence-activated cell sorting; ECL, enhanced chemiluminescence; RT-PCR, reverse transcription-polymerase chain reaction; MMP, mitochondrial membrane potential; DCFDA, 2',7'-dichlorodihydrofluorescein diacetate; NAC, $N$-acetyl cysteine

Key words: Sorbus commixta, apoptosis, reactive oxygen species, mitochondria production was also increased by SCE treatment. However, the SCE-induced cytotoxic effects and the increased expression of proapoptotic proteins, including p53 and p21, and reduced Bcl-2/Bax ratio, could be attenuated by $\mathrm{N}$-acetyl cysteine, an ROS inhibitor. Taken together, these results indicate that SCE is a potent proapoptotic herbal medicine, which exerts its effects via the ROS-mediated mitochondrial pathway.

\section{Introduction}

Apoptosis, a form of programmed cell death, is essential for maintaining fundamental physiological processes, including embryonic development, tissue homeostasis, immune function, tumor suppression and infection resistance (1). Dysregulation of apoptosis is considered to be one of the hallmarks of cancer, since it is associated with uncontrolled cell growth, tumorigenesis, cancer progression and resistance to therapy (2). The apoptotic machinery is complex, and it can be triggered via two different pathways: The extrinsic death-receptor pathway, or the intrinsic mitochondrial pathway $(3,4)$.

Therefore, the restoration of these apoptotic pathways using drugs has been accepted as an important molecular target for cancer treatment $(1,4)$. Thus far, numerous anticancer drugs targeting apoptotic pathways have been developed $(4,5)$. However, demand for novel and improved anticancer drugs is growing (5). Traditional herbal medicines and their natural ingredients, including polyphenols, carotenoids and triterpenes, may be useful resources for developing novel anticancer drugs (6-9). The proapoptotic effects of herbal medicines have been researched extensively in experimental and clinical studies of cancer treatment $(8,9)$.

Sorbus commixta Hedl. (belonging to the Rosaceae family) is a deciduous tree that is native to Japan, the Russian Far East, and Korea (10). The cortex and barks of S. commixta have been used for the treatment of diverse diseases, including asthma, bronchitis, gastritis and edema, in traditional Korean medicine $(11,12)$. Several previous studies have demonstrated that the methanol extract of $S$. commixta has anti-atherosclerotic effects (13-15) and hepatoprotective activity (16). The water extract of S. commixta (SCE) has anti-inflammatory activity (12), and aqueous-ethanol extracts of $S$. commixta 
showed neuroprotective action against amyloid $\beta$ toxicity (17) and protective effects on ultraviolet-induced photo-aging (18). The cancer growth-inhibitory action of S. commixta has not been reported until now. However, the triterpenoid compounds isolated from S. commixta, lupeol and lupenone, have been shown to inhibit the activity of protein phosphatase 1B (19), which is associated with cancer development $(20,21)$.

Therefore, the present study examined the anticancer effect of S. commixta. Firstly, it was demonstrated that SCE can induce apoptosis in human colorectal carcinoma HCT116 cells. The underlying mechanisms of SCE-induced apoptosis were associated with ROS-dependent expression of proapoptotic proteins, including p53, p21 and B-cell lymphoma-2 (Bcl-2)-associated $\mathrm{X}$ protein (Bax). These results suggested that $S$. commixta may be a source from which novel anticancer agents may be developed.

\section{Materials and methods}

Materials. Antibodies against caspase-3 (cat. no. 9665P), caspase-9 (cat. no. 9058P), poly ADP-ribose polymerase (PARP; cat. no. 9542) and p27 (cat. no. 3698) were supplied by Cell Signaling Technology, Inc. (Danvers, MA, USA). The antibody against p21 (cat. no. Ab109199) was provided by Abcam (Cambridge, UK). Antibodies against Bcl-2 (cat. no. NB100-56098) and Bax (cat. no. NB100-56095) were purchased from Novus Biologicals, LLC (Littleton, CO, USA). Antibodies against p53 (cat. no. sc-6243), mouse double minute 2 homology (Mdm2; cat. no. sc-965) and GAPDH (cat. no. sc-32233) were supplied by Santa Cruz Biotechnology, Inc. (Dallas, TX, USA). The antibodies for goat anti-mouse IgG (cat. no. NCI1430KR) and goat anti-rabbit IgG (cat. no. NCI1460KR) were provided by Thermo Fisher Scientific, Inc. (Waltham, MA, USA). Primary antibodies were diluted to $1: 1,000$ and secondary antibodies were diluted to $1: 5,000$. All chemicals, including MTT, tetramethylrhodamine methyl ester perchlorate (TMRM), and $N$-acetyl cysteine (NAC) were obtained from Sigma-Aldrich (Merck KGaA, Darmstadt, Germany), unless otherwise indicated.

Extraction and preparation of plant material. Stem and cortex of S. commixta, which was grown and collected in North Gyeongsang Province, South Korea, in 2012, were purchased from Omniherb Co., Ltd. (Daegu, South Korea). The plant was authenticated by a botanical expert working in the company. A voucher specimen is retained at the School of Korean Medicine, Pusan National University (Yangsan, South Korea). The dried plant material (50 g) was cut and extracted in a liter of distilled water at $100^{\circ} \mathrm{C}$ for $4 \mathrm{~h}$. The extract was passed through filter paper (pore size, $6 \mu \mathrm{m}$; Whatman PLC; GE Healthcare Life Sciences, Little Chalfont, UK), condensed using a Eyela N-1110 rotary evaporator (Tokyo Rikakikai Co., Ltd., Tokyo, Japan) and lyophilized with a freeze dryer (Labconco Corporation, Kansas City, MO, USA). The resulting SCE powder (final yield $3.1 \mathrm{~g}$ ) was dissolved in dimethyl sulfoxide (DMSO) to create a stock solution $(100 \mathrm{mg} / \mathrm{ml})$, and diluted with culture medium prior to use in the experiments.

Cell culture. Hepatocellular carcinoma Hep3B and HepG2 cells, and colon cancer HCT116 cells were provided by the
American Type Culture Collection (Manassas, VA, USA). The cells were cultured with Dulbecco's modified Eagle's medium (Thermo Fisher Scientific, Inc., Waltham, MA, USA) supplemented with L-glutamine (200 mg/l), 10\% (v/v), antibiotics (100 U/ml penicillin and $100 \mu \mathrm{g} / \mathrm{ml}$ streptomycin; Thermo Fisher Scientific, Inc.) and heat-inactivated fetal bovine serum (Sigma-Aldrich; Merck KGaA). The cells were incubated in a humidified cell incubator at $37^{\circ} \mathrm{C}$ in an atmosphere of $5 \% \mathrm{CO}_{2}$ prior to experiments.

Cell viability assay. The viabilities of the cells incubated with various concentrations of SCE were evaluated by MTT assay. Hep3B, HepG2 and HCT116 cells were incubated in 24-well plates with $0,100,200,300,400$ or $500 \mathrm{mg} / \mathrm{ml}$ of SCE for $48 \mathrm{~h}$ at $37^{\circ} \mathrm{C}$. MTT solution $(2.0 \mathrm{mg} / \mathrm{ml})$ was added to each well and the cells were incubated for $4 \mathrm{~h}$ at $37^{\circ} \mathrm{C}$ with $5 \% \mathrm{CO}_{2}$. The culture media were removed, and cells were lysed in DMSO. The amount of formazan crystals, formed by viable cells, was estimated by measuring the absorbance at $540 \mathrm{~nm}$ with a Spectramax M2 microplate reader (Molecular Devices, LLC, Sunnyvale, CA, USA).

Cell cycle analysis for the detection of cells in sub-G1 phase. HCT116 cells $\left(2 \times 10^{6}\right.$ cells) were centrifuged at 2,500 x g and $4^{\circ} \mathrm{C}$ for $10 \mathrm{~min}$, and washed twice in PBS buffer. The cell pellets were gently resuspended in $100 \mu \mathrm{l}$ PBS, and fixed for $30 \mathrm{~min}$ at $4^{\circ} \mathrm{C}$ via serial addition of $200 \mu \mathrm{l}$ PBS containing $10 \%$ ethanol $/ 5 \%$ glycerol, followed by $200 \mu \mathrm{l}$ PBS containing $50 \%$ ethanol $/ 5 \%$ glycerol. The samples were incubated on ice for $5 \mathrm{~min}$, and $100 \%$ ethanol $/ 5 \%$ glycerol solution was added to the cell suspension to make a final volume of $1 \mathrm{ml}$ PBS containing $70 \%$ ethanol $/ 5 \%$ glycerol. The samples were stored at $4^{\circ} \mathrm{C}$ overnight, washed with PBS, centrifuged and resuspended with $12.5 \mu \mathrm{g}$ of RNase (Sigma-Aldrich; Merck $\mathrm{KGaA}$ ) in $250 \mu \mathrm{l}$ of $1.12 \%$ sodium citrate buffer ( $\mathrm{pH} 8.45$ ). The samples were maintained at $37^{\circ} \mathrm{C}$ for $30 \mathrm{~min}$ prior to staining the cellular DNA with $250 \mu \mathrm{l}$ of propidium iodide $(50 \mu \mathrm{g} / \mathrm{ml})$ at room temperature for $30 \mathrm{~min}$. The relative DNA contents of the stained cells were analyzed on a flow cytometer (BD FACSCanto II; BD Biosciences, Franklin Lakes, NJ, USA) with excitation/emission wavelengths of 495/605 nm.

Nuclear staining and fluorescent microscopic observation. For detecting morphological changes associated with apoptosis, HCT116 cells ( $1 \times 10^{5}$ cells) were cultured in the 0,50 , or $100 \mathrm{mg} / \mathrm{ml}$ of SCE for $48 \mathrm{~h}$ at $37^{\circ} \mathrm{C}$. The cells were washed with PBS and fixed with $3.7 \%$ paraformaldehyde/PBS solution for $10 \mathrm{~min}$ at room temperature. The samples were washed with PBS and stained with VECTASHIELD Antifade Mounting Medium with DAPI (Vector Laboratories, Inc., Burlingame, CA, USA) for $10 \mathrm{~min}$ at room temperature. The stained cells were washed twice with PBS and analyzed by confocal microscopy (magnification, x200; ZEISS LSM700 laser; Carl Zeiss AG, Oberkochen, Germany) with excitation/emission wavelengths of 360/460 nm. Four randomly chosen fields of view were captured from each slide.

Western blot analysis. HCT116 cells were treated with the 0 , 50 , or $100 \mathrm{mg} / \mathrm{ml}$ of SCE and total proteins were then extracted from these cells using radioimmunoprecipitation assay buffer 
(Cell Signaling Technology, Inc.) containing a protease inhibitor cocktail (cat. no. 5871, Cell Signaling Technology, Inc.). The samples were centrifuged at $450 \mathrm{x} \mathrm{g}$ for $1 \mathrm{~min}$ and the protein concentrations were estimated by Bio-Rad Protein Assay Kit II (Bio-Rad Laboratories, Inc., Hercules, CA, USA). Equal amounts $(20 \mu \mathrm{g})$ of protein from each sample were fractionated using $10 \%$ SDS-PAGE. The proteins were transferred to nitrocellulose membrane filters (Hybond ECL; GE Healthcare Life Sciences) by electrophoresis. The filters were blocked with $5 \%$ non-fat dry milk or $5 \%$ bovine serum albumin at room temperature for $1 \mathrm{~h}$. The membranes were then incubated with specific primary antibodies against target proteins at $4^{\circ} \mathrm{C}$ overnight. The filters were rinsed twice with TBS containing $0.1 \%$ Tween 20 , and incubated with appropriate secondary horseradish peroxidase-conjugated antibodies at room temperature for $1 \mathrm{~h}$. The bands for proteins of interest were detected using ECL Plus Western Blotting Detection Reagent (GE Healthcare Life Sciences).

Reverse transcription-polymerase chain reaction ( $R T-P C R)$ analysis. Total RNA was extracted from HCT116 cells treated with 0,50 , or $100 \mathrm{mg} / \mathrm{ml}$ of SCE using the GeneJET RNA Purification kit (Thermo Fisher Scientific, Inc.), according to the manufacturer's protocol. The concentration of total RNA was validated using a NanoDrop spectrophotometer (Thermo Fischer Scientific, Inc.). Equal amounts of total RNA $(2 \mu \mathrm{g})$ were used for synthesis of complementary DNA at $70^{\circ} \mathrm{C}$ for $5 \mathrm{~min}, 42^{\circ} \mathrm{C}$ for $60 \mathrm{~min}$, and $94^{\circ} \mathrm{C}$ for $5 \mathrm{~min}$ using oligo-dT primers and AccuPower RT-PreMix (Bioneer Corporation, Daejeon, Korea). Subsequently, $2 \mu \mathrm{g}$ of cDNA was amplified by PCR with the following primers: P53, 5'-GAAACTACT TCCTGAAAACAACGT-3' (sense) and 5'-GCCTCACAA CCTCCGTCAT-3' (antisense); GAPDH (control), 5'-GGA GCCAAAAGGGTCATCAT-3' (sense) and 5'-GTGATGGCA TGGACTGTGGT-3' (antisense). The amplification reactions were performed with the AccuPower PCR-PreMix (Bioneer Corporation), under the following conditions: An initial denaturation at $95^{\circ} \mathrm{C}$ for $5 \mathrm{~min}$; followed by 30 cycles of denaturation for $30 \mathrm{sec}$ at $95^{\circ} \mathrm{C}$; annealing for $30 \mathrm{sec}$ at $60^{\circ} \mathrm{C}$; and extension for $30 \mathrm{sec}$ at $72^{\circ} \mathrm{C}$ with a final extension for $10 \mathrm{~min}$ at $72^{\circ} \mathrm{C}$. Amplified PCR products were electrophoresed in $1.0 \%$ agarose gels, stained with ethidium bromide and detected with GelDoc-It TS Imaging System (UVP, Inc., Upland, CA, USA). The intensities of the bands were quantified using ImageJ software (Version 1.48; National Institutes of Health, Bethesda, MD, USA).

TMRM mitochondrial membrane potential (MMP) assay. For measuring MMP, HCT116 cells were incubated with $250 \mathrm{nM}$ TMRM for $30 \mathrm{~min}$ at $37^{\circ} \mathrm{C}$. The cells were mounted with cover slides in a chamber filled with complete culture medium, and incubated at $37^{\circ} \mathrm{C}$ for $30 \mathrm{~min}$ in cell culture incubator. The fluorescent images of samples were observed and were captured using a ZEISS LSM700 confocal laser scanning microscope (magnification, x200; Carl Zeiss AG) with excitation/emission at 573/600 nm. Four randomly chosen fields of view were captured from each sample. The samples were also analyzed by flow cytometry using a BD FACSCanto II flow cytometry system at excitation/emission wavelengths of $488 / 560 \mathrm{~nm}$.
Determination of reactive oxygen species (ROS). Production of intracellular ROS by each cell was detected with 5-(and-6)-carboxy-2',7'-dichlorodihydrofluorescein diacetate (carboxy-H2DCFDA; Thermo Fisher Scientific, Inc.) according to the manufacturer's protocol. Briefly, the cells were incubated with $100 \mu \mathrm{M}$ carboxy-H2DCFDA in culture medium and incubated at $37^{\circ} \mathrm{C}$ for $30 \mathrm{~min}$. The samples were washed with PBS and their fluorescence was measured using a BD FACSCanto II flow cytometry system at excitation/emission wavelengths of $488 / 525 \mathrm{~nm}$.

Statistical analysis. Data from the cell viability, TMRM and ROS production assays were expressed as percentages relative to the control cells (set at $100 \%$ ), and are presented as the mean \pm standard error of mean (SEM). Data from the cell cycle analysis are shown as a percentage of the total cells analyzed and presented as the mean \pm SEM. The half-maximal inhibitory concentration $\left(\mathrm{IC}_{50}\right)$ values were calculated according to the ' $\log$ (inhibitor) vs. response' equation using GraphPad Prism software (version 5.01; GraphPad Software, Inc., La Jolla, CA, USA). The statistical significance of the differences between the mean values of each group were evaluated by one-way analysis of variance with a Tukey's post hoc test. $\mathrm{P}<0.05$ was considered to indicate a statistically significant difference. All experiments were independently performed at least three times.

\section{Results}

SCE induces apoptotic cell death in HCT116 cells. Initially, the cytotoxic effect of SCE was examined in three different cancer cell lines (Hep3B, HepG2 and HCT116). The results showed that SCE treatment produced dose-dependent cytotoxicity in all three cell lines (Fig. 1). The $\mathrm{IC}_{50}$ values for SCE in the Hep3B, HepG2 and HCT116 cells were $300.1(\mathrm{P}<0.0001)$, $237.8(\mathrm{P}<0.0001)$ and $77.7 \mu \mathrm{g} / \mathrm{ml}(\mathrm{P}<0.0001)$, respectively. As the cytotoxic effect of SCE was most potent in the colon cancer HCT116 cells, the HCT116 cell line was selected for subsequent experiments. To elucidate whether the cytotoxic effect of SCE was due to apoptotic cell death, the cell cycle of SCE-treated HCT116 cells was investigated. The data demonstrated that the population of sub-G1 phase cells was increased by SCE treatment in a dose-dependent manner $(\mathrm{P}<0.0001$; Fig. $2 \mathrm{~A}$ and $\mathrm{B})$. In addition, nucleic DNA was degraded following SCE treatment, as measured using DAPI staining (Fig. 2C). These results suggest that $\mathrm{SCE}$-induced cell death involves apoptosis.

SCE induces apoptosis through the mitochondrial pathway. To examine the mechanism underlying SCE-induced apoptosis, the levels of certain proteins involved in the apoptosis cascade were assessed. The results demonstrated that SCE reduced the levels of the proforms of caspase-9, caspase- 3 and PARP, whereas the cleaved forms of caspase-3 and PARP were increased by SCE treatment (Fig. 2D) Cleaved and pro-PARP were detected using the same antibody and analyzed according to their molecular weights. To evaluate the effect of SCE on the mitochondrial membrane stability, a TMRM MMP assay was performed. The results from the fluorescent microscopic observation and fluorescence-activated cell sorting analysis demonstrated that MMP was reduced by SCE treatment in 

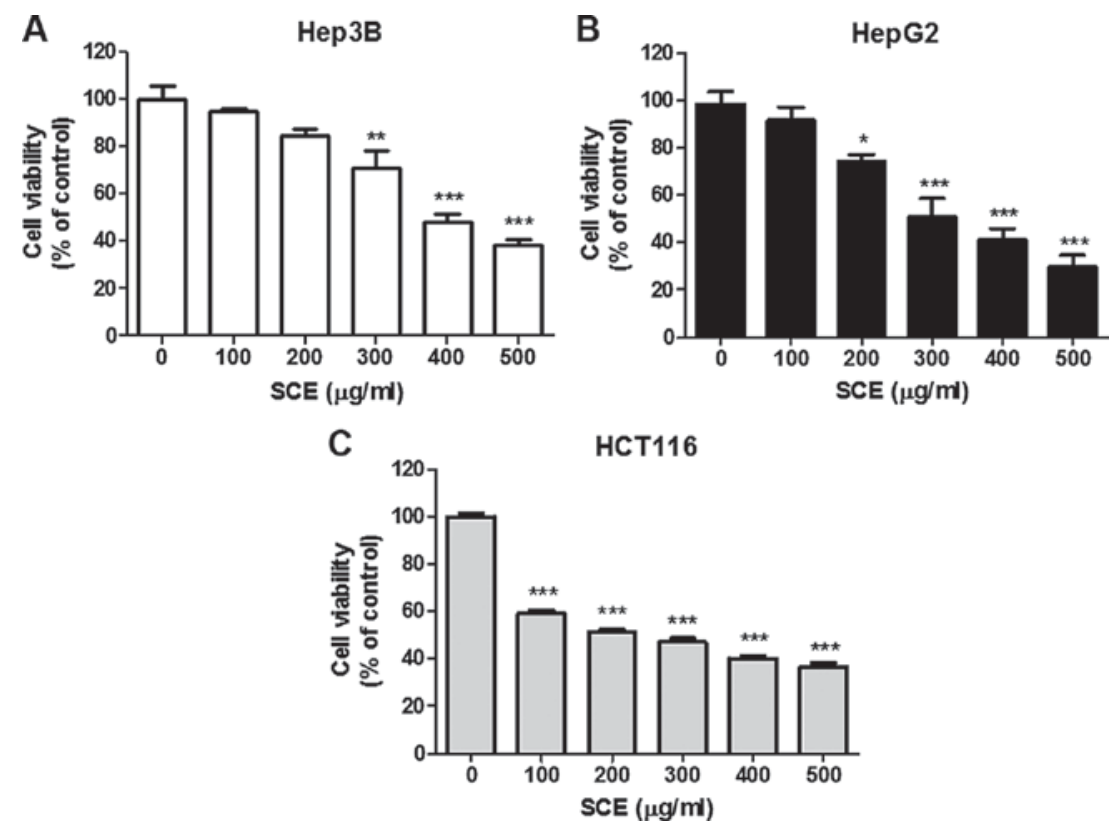

Figure 1. SCE has a cytotoxic effect on Hep3B, HepG2 and HCT116 cells. (A) Hep3B, (B) HepG2 and (C) HCT116 cells were plated in 24-well culture flasks and cultured with the indicated concentrations of SCE for $48 \mathrm{~h}$. The viabilities of these cells were examined by MTT assay, which indicated SCE dose-dependent cytotoxicity in all three cell lines. ${ }^{*} \mathrm{P}<0.05,{ }^{* *} \mathrm{P}<0.01$ and ${ }^{* * * *} \mathrm{P}<0.001$, compared with the control $(0 \mathrm{mg} / \mathrm{ml} \mathrm{SCE})$. SCE, Sorbus commixta water extract.
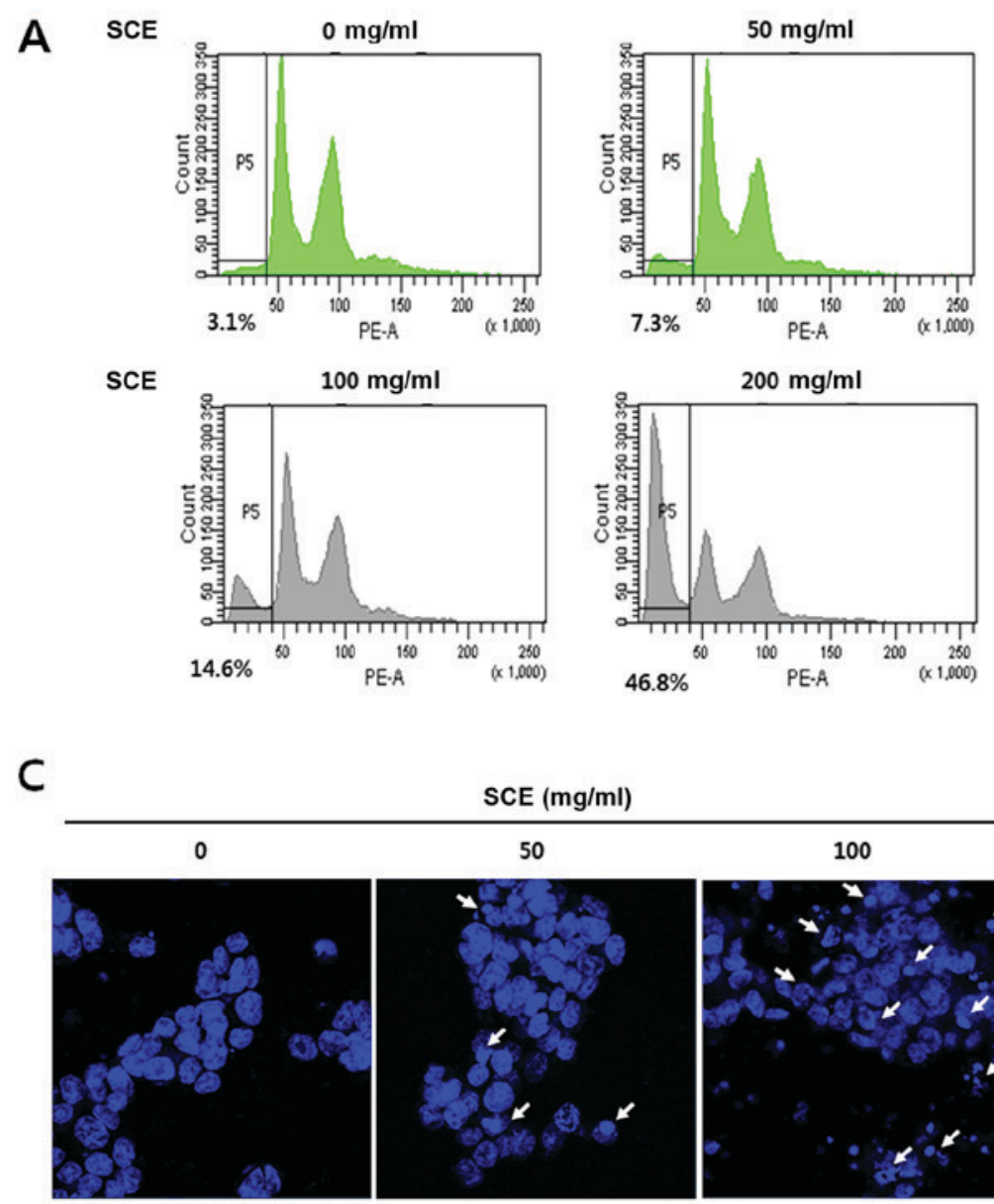

\section{$\operatorname{SCE}(\mathrm{mg} / \mathrm{ml})$}

50

100
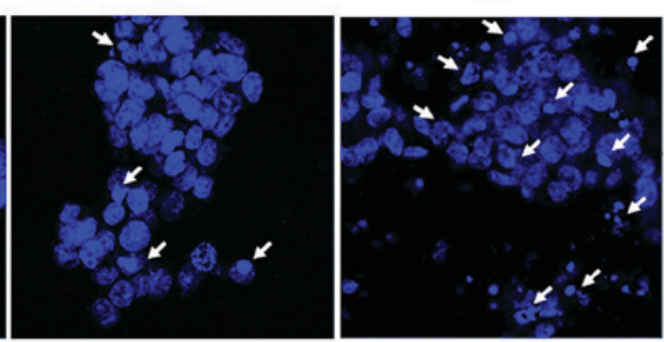

B
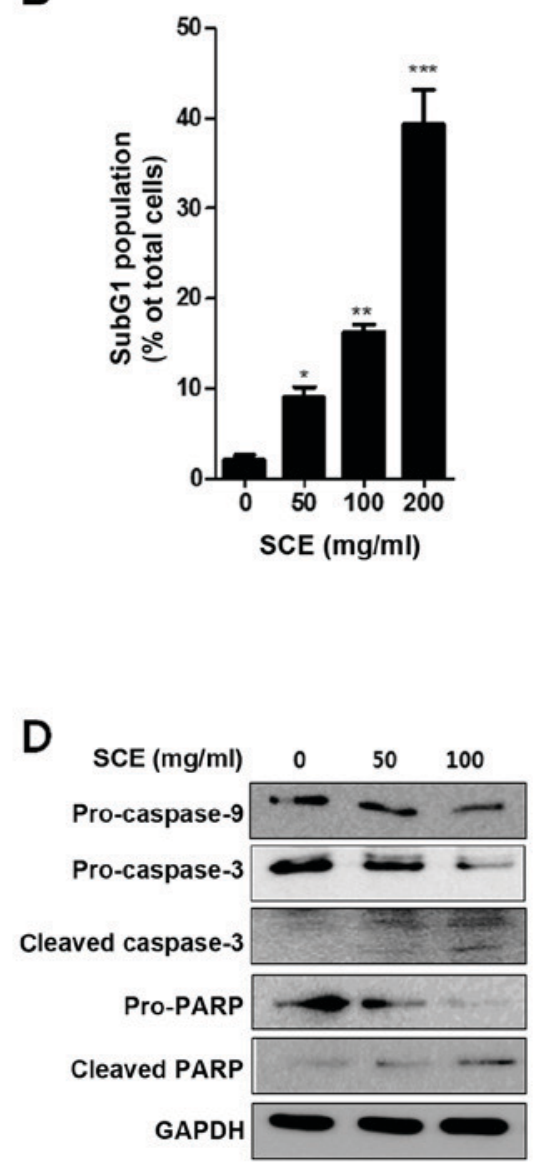

Figure 2. SCE induces apoptotic cell death in HCT116 cells. HCT116 cells were cultured with the indicated concentrations of SCE for $48 \mathrm{~h}$. (A) The DNA contents of the cells were evaluated by FACS analysis using propidium iodide staining (indicated with PE-A). Representative data from the cell cycle analyses are shown. (B) The percentage of sub-G1 phase cells (P5) from three different FACS analyses were calculated and presented as the mean \pm standard error of the mean. ${ }^{*} \mathrm{P}<0.05,{ }^{* *} \mathrm{P}<0.01$ and ${ }^{* * *} \mathrm{P}<0.001$, compared with the control ( $\left.0 \mathrm{mg} / \mathrm{ml} \mathrm{SCE}\right)$. (C) Degradation of nucleic DNA was evaluated by DAPI staining and confocal microscopic observation (magnification, x200). Damaged nuclei are indicated by the arrows. (D) Equal amounts of the proteins extracted from SCE-treated cells were subjected to western blot analysis for detection of apoptotic signaling molecules, including caspase-9, caspase-3 and PARP. The expression of GAPDH was used as an internal control. SCE, Sorbus commixta water extract; FACS, fluorescence-activated cell sorting; PARP, poly ADP-ribose polymerase. 
A

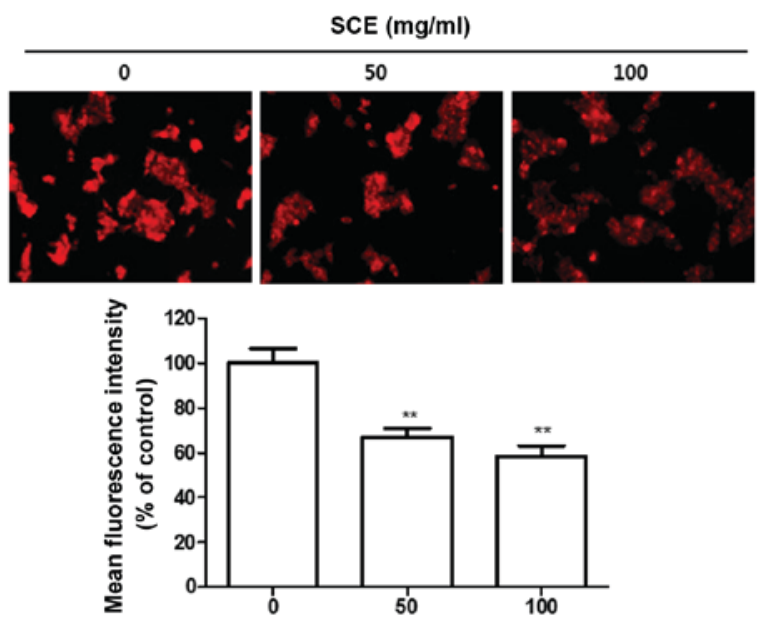

B
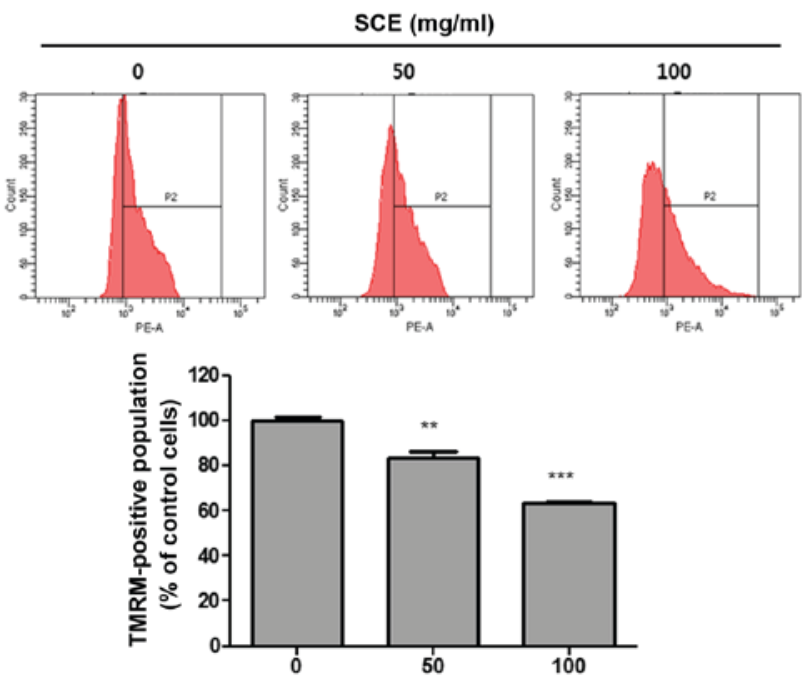

Figure 3. SCE reduces mitochondrial membrane stability. HCT116 cells were treated with the indicated concentrations of SCE for $24 \mathrm{~h}$ and then stained with TMRM for the detection of membrane stability. (A) Representative images of TMRM-stained mitochondria were captured by fluorescence microscopy (magnification, x200) and mean fluorescence intensities (presented as the mean \pm SEM) were calculated as a percentage of the control ( $0 \mathrm{mg} / \mathrm{ml} \mathrm{SCE}) .{ }^{* *} \mathrm{P}<0.01$ compared with the control. (B) The TMRM-stained cells were analyzed by flow cytometry with excitation/emission wavelengths at $488 / 560 \mathrm{~nm}$ (indicated with PE-A). The population of TMRM-positive HCT116 cells (P2) was analyzed by FACS analysis. Representative FACS results are shown as the mean $\pm \mathrm{SEM} .{ }^{* *} \mathrm{P}<0.01$ and ${ }^{* * *} \mathrm{P}<0.001$ compared with control. TMRM, tetramethylrhodamine methyl ester perchlorate; SCE, Sorbus commixta water extract; SEM, standard error of mean; FACS, fluorescence-activated cell sorting.

a dose-dependent manner (Fig. 3; $\mathrm{P}=0.0028$ for panel A and $\mathrm{P}<0.0001$ for panel $\mathrm{B})$.

SCE increases p53-associated proapoptotic pathways. To examine the effect of SCE on the stability of mitochondria, the balance of Bax and Bcl-2 was examined. The data showed that SCE increased the amount of proapoptotic Bax and reduced that of antiapoptotic Bcl-2 (Fig. 4A). In addition, the protein expression levels of p21 and p27 were dose-dependently increased by SCE treatment (Fig. 4B). RT-PCR and western blotting were then used to confirm whether the expression of p53 was altered by SCE treatment. The results showed that SCE increased the expression of p53 at the mRNA and protein
A
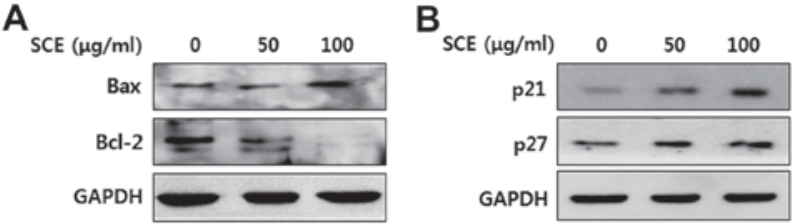

$\mathrm{C}_{\mathrm{sc}}$

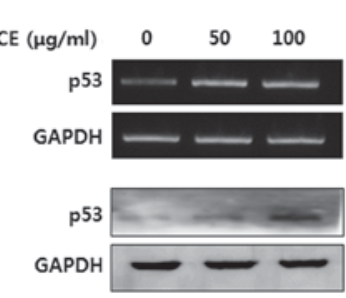

D

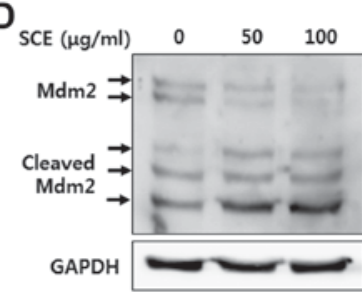

Figure 4. SCE induces apoptosis through the p53-mediated mitochondrial pathway. HCT116 cells were treated with the indicated concentrations of SCE for $48 \mathrm{~h}$, and total mRNA and protein were extracted. (A) Equal amounts of the proteins were subjected to western blot analysis for the detection of Bax and Bcl-2 proteins, which are involved in mitochondrial stability. (B) The protein expression levels of $\mathrm{p} 21$ and $\mathrm{p} 27$ were evaluated by western blot analysis. (C) Expression levels of p53 were examined by reverse transcription polymerase-chain reaction and western blot analysis. (D) The protein expression levels of uncleaved and cleaved Mdm2 were estimated by western blot analysis. GAPDH was used as an internal control for all experiments. Bcl-2, B-cell lymphoma-2; Bax, Bcl-2-associated X protein; SCE, Sorbus commixta water extract; $\mathrm{Mdm} 2$, mouse double minute 2 homology.

levels (Fig. 4C). Furthermore, Mdm2 protein, an important negative regulator of p53, was cleaved by SCE treatment (Fig. 4D). From these results, it was hypothesized that SCE increases the expression of the tumor suppressor p 53 through transcriptional and posttranslational regulation.

SCE-induced apoptosis involves ROS production. It was examined whether the production of ROS was increased by SCE treatment. The data showed that SCE dose-dependently increased ROS production in HCT116 cells. Furthermore, the addition of a ROS scavenger, NAC $(5 \mathrm{mM})$, significantly reduced the SCE-stimulated intracellular ROS levels (Fig. 5A; $\mathrm{P}=0.0006$ ). To elucidate whether ROS production was involved in the p53-mediated apoptosis of HCT116 cells, cell viability was assessed. The results revealed that the SCE-induced death of HCT116 cells was attenuated by NAC ( $\mathrm{P}=0.0001$; Fig. 5B). In addition, the SCE-stimulated expression of proapoptotic proteins, including p53, p21 and Bax, was reduced by NAC treatment. By contrast, the expression of anti-apoptotic protein, Bcl-2, was recovered by NAC (Fig. 5C). From these results, it was suggested that SCE induces apoptotic cell death via ROS-mediated mitochondrial damage (Fig. 6).

\section{Discussion}

Medicinal herbs and their ingredient compounds are considered important and valuable resources for anticancer drug development (22). These natural products can contribute to the prevention or inhibition of tumor growth through targeting diverse molecular mechanisms $(6,9)$. Among these anticancer mechanisms, inducing apoptotic cell death is one of most important mechanisms of killing cancer cells with minimal side effects on normal tissues $(4,23)$. Thus, herbal medicines and natural compounds have been studied and 
A

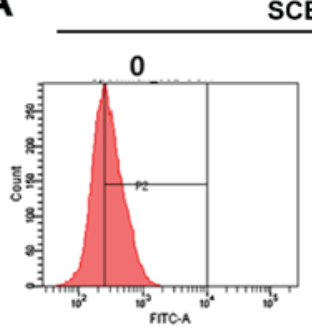

$\operatorname{SCE}(\mathrm{mg} / \mathrm{ml})$
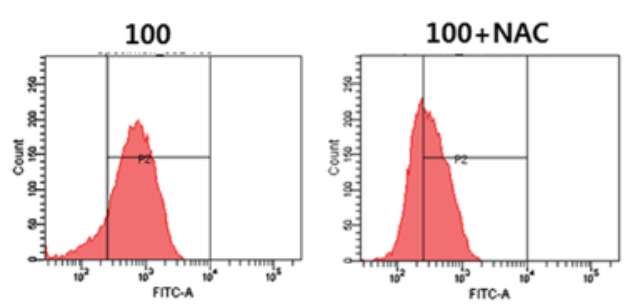

B

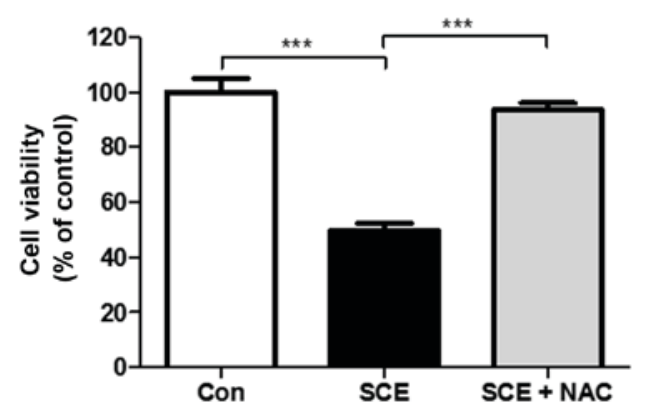

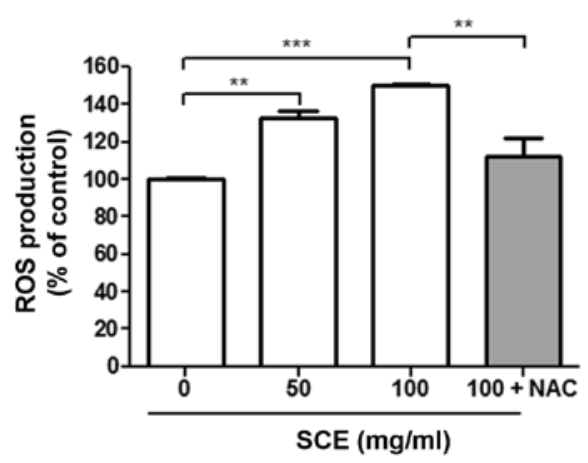

C

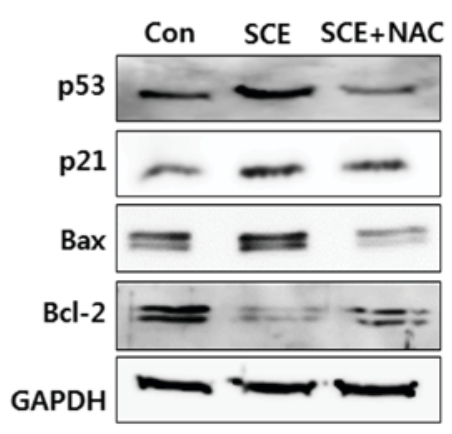

Figure 5. Apoptotic effects of SCE are mediated in a ROS-dependent manner. (A) HCT116 cells were treated with the indicated concentrations of SCE, or $100 \mathrm{mg} / \mathrm{ml} \mathrm{SCE}$ supplemented with NAC $(5 \mathrm{mM})$ for $24 \mathrm{~h}$. The production of ROS was estimated by fluorescence-activated cell sorting analysis with DCFDA staining. The fluorescence was analyzed by excitation/emission wavelength at 488/525 nm (indicated with PE-A). The representative figures are shown and DCFDA-positive cells (P2) were calculated as a percentage of the control (presented as the mean \pm SEM). ${ }^{* *} \mathrm{P}<0.01$ and ${ }^{* * * *} \mathrm{P}<0.001$ compared with the control. (B) The HCT116 cells were treated with SCE $(100 \mu \mathrm{g} / \mathrm{ml})$ with or without NAC $(5 \mathrm{mM})$. The viabilities of the cells were measured by MTT assay and shown as a percentage of the control. ${ }^{* * *} \mathrm{P}<0.001$ compared with the control. (C) The total proteins were extracted from HCT116 cells treated with SCE $(100 \mu \mathrm{g} / \mathrm{ml})$ with or without NAC (5 mM). The expression levels of p53, p21, Bax, Bcl-2 and Mdm2 were examined by western blot analysis. The expression of GAPDH was used as an internal control. SCE, Sorbus commixta water extract; Bcl-2, B-cell lymphoma-2; Bax, Bcl-2-associated X protein; DCFDA, 2',7'-dichlorodihydrofluorescein diacetate; NAC, N-acetyl cysteine.

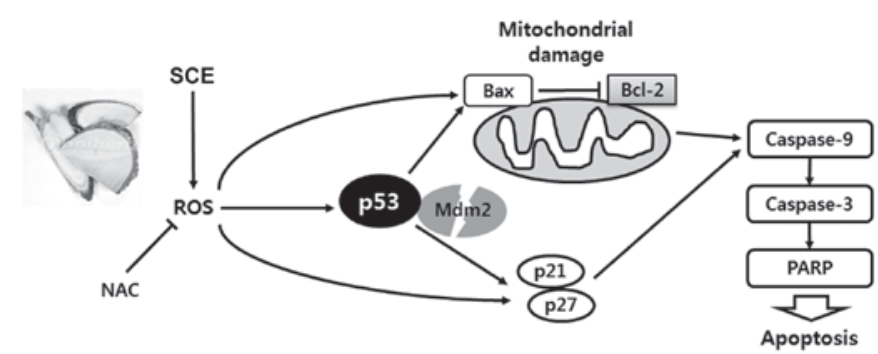

Figure 6. Proposed schematic representation of the mechanism underlying the proapoptotic effect of SCE. SCE induces ROS-dependent expression of proapoptotic proteins, including $\mathrm{p} 53, \mathrm{p} 21$ and Bax. These proteins induce the apoptosis of HCT116 cells through activating the intrinsic mitochondrial pathway. SCE, Sorbus commixta water extract; ROS, reactive oxygen species; Bcl-2, B-cell lymphoma-2; Bax, Bcl-2-associated X protein; NAC, $\mathrm{N}$-acetyl cysteine; Mdm2, mouse double minute 2 homology; PARP, poly ADP-ribose polymerase.

found to possess proapoptotic properties against diverse types of cancer $(22,23)$. The present study showed that SCE has a cytotoxic effect on several cancer cell lines, including Hep3B,
HepG2 and HCT116 cells, through inducing apoptotic cell death (Figs. 1 and 2). Although natural anticancer compounds activate diverse cellular signaling pathways, the mechanisms of apoptosis are concentrated to two major pathways: The extrinsic death-receptor pathway, and the intrinsic mitochondrial pathway (1). In the present study, the results indicated that SCE-induced apoptosis is mediated by a reduction in MMP in colon cancer HCT116 cells (Fig. 3). The MMP is predominantly regulated by the balance of $\mathrm{Bcl}-2$ family proteins, including Bcl-2 and Bax (24). The present results also showed that SCE reduced the ratio of Bcl-2 to Bax (Fig. 4A).

Tumor suppressor genes, including p53, p21 and p27, are the main molecular targets for several herbal drugs and their ingredients (25). Certain herbal medicines and natural products, including Scutellaria baicalensis (26), Gleditsia sinensis (27), ginsenoside Rh2 (28) and epigallocatechin gallate (29,30), have been shown to increase the expression of p53 and subsequently induce apoptosis of cancer cells. p21 and p27 are known to be proapoptotic proteins, as well as cell cycle regulators $(31,32)$. The results from the present study demonstrated that the expression of the tumor suppressors p53, p21 and p27 were increased 
by SCE treatment (Fig. 4B). In addition, p53 regulates various proapoptotic pathways, including the balance of $\mathrm{Bcl}-2 / \mathrm{Bax}$ and the expression of p21 $(33,34)$. The present results showed consistency with these previous studies.

The expression of p53 can be induced by diverse cellular stress stimuli, including ultraviolet radiation, DNA damage, ribonucleotide depletion, hypoxia, heat shock and exposure to $\operatorname{ROS}(33,35)$. The expression of p53 is tightly controlled by several levels of regulation: Protein stabilization involving $\mathrm{Mdm} 2$ regulation, anti-repression mediated by acetylation and phosphorylation, and promoter-specific activation involving additional posttranslational modifications and cofactor recruitment (36). Mdm2 binds to p53 and enhances its degradation through the E3 ligase-mediated ubiquitination pathway $(36,37)$. The N-terminally truncated form of $\mathrm{Mdm} 2$ without the RING finger domain also binds to $\mathrm{p} 53$, but this promotes $\mathrm{p} 53$ stability $(38,39)$. In the present study, the expression of p53 was increased by SCE treatment at the mRNA and protein levels. In addition, $\mathrm{Mdm} 2$, a major negative posttranslational regulator of p53, was cleaved by SCE treatment (Fig. 4C and D). These results suggested that SCE induced p53 expression by activating transcription and enhancing protein stability.

The association between ROS and p53 is bidirectional: ROS can be a downstream mediator of p53-dependent apoptosis as well as upstream inducer of p53 expression (40-42). However, it is evident that excessive production of intracellular ROS is a major mediator of p53-mediated apoptosis $(42,43)$. In the present study, the results showed that SCE stimulated the production of ROS in HCT116 cells (Fig. 5A). SCE-induced cell death was abolished by treatment with a ROS scavenger, NAC (Fig. 5B). In addition, the SCE-stimulated expression of p53 was reduced by NAC treatment (Fig. 5C). Thus, it was hypothesized that ROS produced by SCE treatment may act as inducers of p53 expression. The other proapoptotic proteins, including Bax and p21, were also induced by SCE treatment and abolished by the addition of NAC. By contrast, the antiapoptotic protein Bcl-2 was reduced by SCE treatment and recovered by NAC treatment (Fig. 5C).

Previous studies demonstrated that ROS can produce an imbalance of the $\mathrm{Bcl}-2 / \mathrm{Bax}$ ratio and increase the expression of p21 and p27 through p53-dependent or -independent pathways $(44,45)$. The activation of caspase- 9 and the initiation of the intrinsic apoptosis cascade can be activated by an imbalance of Bcl-2/Bax and subsequent reduction of MMP (24). In addition, previous studies showed that p21 and p27 directly enhance the cleavage of caspase- $9(31,32)$. Thus, it was postulated that SCE induced the apoptosis of cancer cells through ROS-mediated activation of the intrinsic mitochondrial pathway. The proapoptotic proteins p53, p21 and Bax were involved in the ROS-mediated activation of the apoptosis cascade (Fig. 6).

The components of $S$. commixta have been reported by several previous studies $(19,46,47)$. Among them, several compounds, including lupeol, $\beta$-sitosterol and ursolic acid $(48,49)$, have been reported as anticancer agents. In addition, several studies reported that S. commixta has anti-atherosclerotic (13-15), hepatoprotective (16), anti-inflammatory activities (12), and can exert neuroprotective (17) and anti-photo-aging effects (18). However, the inhibitory action of $S$. commixta on the growth of cancer and its underlying mechanisms have not been studied until now. The present study showed that the crude water extract of
S. commixta has a cytotoxic effect on several lines of liver and colon cancer cells. To elucidate the precise compounds that are responsible for the induction of apoptosis, additional extensive studies are required.

In summary, the present study demonstrated that SCE has a proapoptotic effect on human colon carcinoma HCT116 cells. The ROS-dependent expression of proapoptotic proteins, including p53, p21 and Bax, was involved in the underlying mechanisms of SCE-induced apoptosis. To the best of our knowledge, this is the first study demonstrating the proapoptotic effect of SCE and suggesting the possibility of SCE as a resource for anticancer drug development.

\section{Acknowledgements}

The present study was supported by the National Research Foundation of Korea grant funded by the Ministry of Science, ICT \& Future Planning, Korean government (grant no. 2014R1A5A20009936).

\section{Competing interests}

The authors declare that they have no competing interests.

\section{References}

1. Baig S, Seevasant I, Mohamad J, Mukheem A, Huri HZ and Kamarul T: Potential of apoptotic pathway-targeted cancer therapeutic research: Where do we stand? Cell Death Dis 7: e2058, 2016.

2. Hanahan D and Weinberg RA: Hallmarks of cancer: The next generation. Cell 144: 646-674, 2011.

3. Fulda S and Debatin KM: Extrinsic versus intrinsic apoptosis pathways in anticancer chemotherapy. Oncogene 25: 4798-4811, 2006.

4. Pistritto G, Trisciuoglio D, Ceci C, Garufi A and D'Orazi G: Apoptosis as anticancer mechanism: Function and dysfunction of its modulators and targeted therapeutic strategies. Aging (Albany NY) 8: 603-619, 2016.

5. Wang H, Yin Y, Wang P, Xiong C, Huang L, Li S, Li X and Fu L: Current situation and future usage of anticancer drug databases. Apoptosis 21: 778-794, 2016.

6. Gill BS, Kumar S and Navgeet: Triterpenes in cancer: Significance and their influence. Mol Biol Rep 43: 881-896, 2016.

7. Milani A, Basirnejad M, Shahbazi S and Bolhassani A: Carotenoids: Biochemistry, pharmacology and treatment. Br J Pharmacol 174: 1290-1324, 2017.

8. Niedzwiecki A, Roomi MW, Kalinovsky $\mathrm{T}$ and Rath M: Anticancer efficacy of polyphenols and their combinations. Nutrients 8: E552, 2016.

9. Zhang YS, Shen Q and Li J: Traditional Chinese medicine targeting apoptotic mechanisms for esophageal cancer therapy. Acta Pharmacol Sin 37: 295-302, 2016.

10. McAllister H: The genus sorbus: Mountain ash and other rowans. Royal Botanic Gardens, KEW, Surrey, UK, 2005.

11. Yang $\mathrm{G}$ and An HJ: $\beta$-sitosteryl-3-O- $\beta$-glucopyranoside isolated from the bark of Sorbus commixta ameliorates pro-inflammatory mediators in RAW 264.7 macrophages. Immunopharmacol Immunotoxicol 36: 70-77, 2014.

12. Yu T, Lee YJ, Jang HJ, Kim AR, Hong S, Kim TW, Kim MY, Lee J, Lee YG and Cho JY: Anti-inflammatory activity of Sorbus commixta water extract and its molecular inhibitory mechanism. J Ethnopharmacol 134: 493-500, 2011

13. Kang DG, Sohn EJ, Lee AS, Kim JS, Lee DH and Lee HS: Methanol extract of Sorbus commixta cortex prevents vascular inflammation in rats with a high fructose-induced metabolic syndrome. Am J Chin Med 35: 265-277, 2007.

14. Sohn EJ, Kang DG, Choi DH, Lee AS, Mun YJ, Woo WH, Kim JS and Lee HS: Effect of methanol extract of Sorbus cortex in a rat model of L-NAME-induced atherosclerosis. Biol Pharm Bull 28: 1239-1243, 2005 
15. Sohn EJ, Kang DG, Mun YJ, Woo WH and Lee HS: Anti-atherogenic effects of the methanol extract of Sorbus cortex in atherogenic-diet rats. Biol Pharm Bull 28: 1444-1449, 2005.

16. Lee SO, Lee HW, Lee IS and Im HG: The pharmacological potential of Sorbus commixta cortex on blood alcohol concentration and hepatic lipid peroxidation in acute alcohol-treated rats. J Pharm Pharmacol 58: 685-693, 2006.

17. Liu QF, Lee JH, Kim YM, Lee S, Hong YK, Hwang S, Oh Y, Lee K, Yun HS, Lee IS, et al: In vivo screening of traditional medicinal plants for neuroprotective activity against $\mathrm{A} \beta 42$ cytotoxicity by using drosophila models of Alzheimer's disease. Biol Pharm Bull 38: 1891-1901, 2015.

18. Bae JT, Sim GS, Kim JH, Pyo HB, Yun JW and Lee BC: Antioxidative activity of the hydrolytic enzyme treated Sorbus commixta Hedl. and its inhibitory effect on matrix metalloproteinase-1 in UV irradiated human dermal fibroblasts. Arch Pharm Res 30: 1116-1123, 2007.

19. Na M, Kim BY, Osada H and Ahn JS: Inhibition of protein tyrosine phosphatase 1B by lupeol and lupenone isolated from Sorbus commixta. J Enzyme Inhib Med Chem 24: 1056-1059, 2009.

20. Nikolaienko RM, Agyekum B and Bouyain S: Receptor protein tyrosine phosphatases and cancer: New insights from structural biology. Cell Adh Migr 6: 356-364, 2012.

21. Ostman A, Hellberg C and Böhmer FD: Protein-tyrosine phosphatases and cancer. Nat Rev Cancer 6: 307-320, 2006.

22. Millimouno FM, Dong J, Yang L, Li J and Li X: Targeting apoptosis pathways in cancer and perspectives with natural compounds from mother nature. Cancer Prev Res (Phila) 7: 1081-1107, 2014.

23. Safarzadeh E, Sandoghchian Shotorbani S and Baradaran B Herbal medicine as inducers of apoptosis in cancer treatment. Adv Pharm Bull 4: 421-427, 2014.

24. Brunelle JK and Letai A: Control of mitochondrial apoptosis by the Bcl-2 family. J Cell Sci 122: 437-441, 2009.

25. Kitagishi Y, Kobayashi M and Matsuda S: Protection against cancer with medicinal herbs via activation of tumor suppressor. J Oncol 2012: 236530, 2012.

26. Gao J, Morgan WA, Sanchez-Medina A and Corcoran O The ethanol extract of Scutellaria baicalensis and the active compounds induce cell cycle arrest and apoptosis including upregulation of p53 and Bax in human lung cancer cells. Toxicol Appl Pharmacol 254: 221-228, 2011.

27. Lee SJ, Park K, Ha SD, Kim WJ and Moon SK: Gleditsia sinensis thorn extract inhibits human colon cancer cells: The role of ERK1/2, G2/M-phase cell cycle arrest and p53 expression. Phytother Res 24: 1870-1876, 2010.

28. Li B, Zhao J, Wang CZ, Searle J, He TC, Yuan CS and Du W: Ginsenoside Rh2 induces apoptosis and paraptosis-like cell death in colorectal cancer cells through activation of p53. Cancer Lett 301: 185-192, 2011

29. Hastak K, Agarwal MK, Mukhtar H and Agarwal ML: Ablation of either $\mathrm{p} 21$ or Bax prevents p53-dependent apoptosis induced by green tea polyphenol epigallocatechin-3-gallate. FASEB J 19: 789-791, 2005.

30. Masuda M, Suzui M and Weinstein IB: Effects of epigallocatechin-3-gallate on growth, epidermal growth factor receptor signaling pathways, gene expression, and chemosensitivity in human head and neck squamous cell carcinoma cell lines. Clin Cancer Res 7: 4220-4229, 2001.

31. Abbas T and Dutta A: p21 in cancer: Intricate networks and multiple activities. Nat Rev Cancer 9: 400-414, 2009.
32. Levkau B, Koyama H, Raines EW, Clurman BE, Herren B, Orth K, Roberts JM and Ross R: Cleavage of p21Cip1/Waf1 and p27Kip1 mediates apoptosis in endothelial cells through activation of Cdk2: Role of a caspase cascade. Mol Cell 1: 553-563, 1998.

33. Chipuk JE and Green DR: Cytoplasmic p53: Bax and forward. Cell Cycle 3: 429-431, 2004.

34. Miyashita T, Krajewski S, Krajewska M, Wang HG, Lin HK, Liebermann DA, Hoffman B and Reed JC: Tumor suppressor p53 is a regulator of bcl-2 and bax gene expression in vitro and in vivo. Oncogene 9: 1799-1805, 1994

35. Oren M: Regulation of the p53 tumor suppressor protein. J Biol Chem 274: 36031-36034, 1999.

36. Kruse JP and Gu W: Modes of p53 regulation. Cell 137: 609-622, 2009.

37. Ryan KM, Phillips AC and Vousden KH: Regulation and function of the p53 tumor suppressor protein. Curr Opin Cell Biol 13: 332-337, 2001.

38. Oliver TG, Meylan E, Chang GP, Xue W, Burke JR, Humpton TJ, Hubbard D, Bhutkar A and Jacks T: Caspase-2-mediated cleavage of Mdm 2 creates a p53-induced positive feedback loop. Mol Cell 43: 57-71, 2011.

39. Pochampally R, Fodera B, Chen L, Shao W, Levine EA and Chen J: A $60 \mathrm{kd}$ MDM2 isoform is produced by caspase cleavage in non-apoptotic tumor cells. Oncogene 17: 2629-2636, 1998.

40. Macip S, Igarashi M, Berggren P, Yu J, Lee SW and Aaronson SA: Influence of induced reactive oxygen species in p53-mediated cell fate decisions. Mol Cell Biol 23: 8576-8585, 2003.

41. Johnson TM, Yu ZX, Ferrans VJ, Lowenstein RA and Finkel T: Reactive oxygen species are downstream mediators of p53-dependent apoptosis. Proc Natl Acad Sci USA 93: 11848-11852, 1996.

42. Liu B, Chen Y and St Clair DK: ROS and p53: A versatile partnership. Free Radic Biol Med 44: 1529-1535, 2008.

43. Polyak K, Xia Y, Zweier JL, Kinzler KW and Vogelstein B: A model for p53-induced apoptosis. Nature 389: 300-305, 1997

44. Choi D, Hwang S, Lee E, Yoon S, Yoon BK and Bae D: Expression of mitochondria-dependent apoptosis genes (p53, Bax, and $\mathrm{Bcl}-2$ ) in rat granulosa cells during follicular development. J Soc Gynecol Investig 11: 311-317, 2004.

45. Yang Y, Karakhanova S, Hartwig W, D'Haese JG, Philippov PP, Werner J and Bazhin AV: Mitochondria and mitochondrial ROS in cancer: Novel targets for anticancer therapy. J Cell Physiol 231: 2570-2581, 2016.

46. Raudone L, Raudonis R, Gaivelytė K, Pukalskas A, Viškelis P, Venskutonis PR and Janulis V: Phytochemical and antioxidant profiles of leaves from different Sorbus L. species. Nat Prod Res 29: 281-285, 2015.

47. Bhatt LR, Bae MS, Kim BM, Oh GS and Chai KY: A chalcone glycoside from the fruits of Sorbus commixta Hedl. Molecules 14: 5323-5327, 2009

48. Liu Y, Bi T, Dai W, Wang G, Qian L, Shen G and Gao Q: Lupeol induces apoptosis and cell cycle arrest of human osteosarcoma cells through PI3K/AKT/mTOR pathway. Technol Cancer Res Treat 15: NP16-NP24, 2016.

49. Sook SH, Lee HJ, Kim JH, Sohn EJ, Jung JH, Kim B, Kim JH, Jeong SJ and Kim SH: Reactive oxygen species-mediated activation of AMP-activated protein kinase and c-Jun N-terminal kinase plays a critical role in beta-sitosterol-induced apoptosis in multiple myeloma U266 cells. Phytother Res 28: 387-394, 2014.

This work is licensed under a Creative Commons Attribution-NonCommercial-NoDerivatives 4.0 International (CC BY-NC-ND 4.0) License. 